NBER WORKING PAPER SERIES

\title{
ECONOMIES OF SCALE IN THE HOUSEHOLD: PUZZLES AND PATTERNS FROM THE AMERICAN PAST
}

\author{
Trevon D. Logan \\ Working Paper 13869 \\ http://www.nber.org/papers/w13869 \\ NATIONAL BUREAU OF ECONOMIC RESEARCH \\ 1050 Massachusetts Avenue \\ Cambridge, MA 02138 \\ March 2008
}

I thank Louis Cain, Dora L. Costa, Matthew S. Lewis, Muna S. Meky, Joel Moykr, Joseph M. Newhard, Paul Rhode, Gianni Tonolio and seminar participants at Ohio State, Indiana, McGill, Northwestern, Duke, the NBER Cohort Studies Conference and Summer Institute, and the AEA Pipeline Conference for helpful discussions. Yasin Akcelik and Yunhui Tan provided excellent research assistance. The usual disclaimer applies. The views expressed herein are those of the author(s) and do not necessarily reflect the views of the National Bureau of Economic Research.

NBER working papers are circulated for discussion and comment purposes. They have not been peerreviewed or been subject to the review by the NBER Board of Directors that accompanies official NBER publications.

(C) 2008 by Trevon D. Logan. All rights reserved. Short sections of text, not to exceed two paragraphs, may be quoted without explicit permission provided that full credit, including $\odot$ notice, is given to the source. 
Economies of Scale in the Household: Puzzles and Patterns from the American Past

Trevon D. Logan

NBER Working Paper No. 13869

March 2008

JEL No. D1,I3,J1,N3

\begin{abstract}
$\underline{\text { ABSTRACT }}$
Household economies of scale arise when households with multiple members share public goods, making larger households better off at lower per capita expenditures. While estimates of household economies of scale are critical for measuring income and living standards, we do not know how these scale economies change over time. I use American household expenditure surveys to produce the first comparable historical estimates of household scale economies. I find that scale economies changed significantly from 1888 to 1935 for all expenditure categories considered (food, clothing, entertainment, and housing), but not all trends in scale economies are consistent with theoretical predictions. I use these historical estimates of household scale economies to resolve several theoretical and empirical puzzles in the literature. I find that existing explanations for puzzles in the household economies of scale literature do not hold in the past. As such, our notions about household economies of scale must be reassessed in light of this historical evidence.
\end{abstract}

Trevon D. Logan

The Ohio State University

410 Arps Hall

1945 North High Street

Columbus, $\mathrm{OH} 43210$

and NBER

logan.155@osu.edu 


\section{Introduction}

In one example of economies of scale, households with multiple members are able to achieve the same standard of living at lower per capita expenditures on public goods than smaller households. For example, if two adults unite to form one household, the couple will be better off as they can share public goods - such as housing - lowering per capita expenditure on them. The couple can funnel these savings into increased consumption of public goods - more spacious housing than either could afford separately - making each member better off than they were when they lived by themselves. The basic idea has strong intuitive appeal; living standards for households of different sizes could be equated with lower per capita expenditures for larger households who are able to economize on public goods. Household economies of scale are therefore fundamental to the measurement of living standards. Measuring the distribution of income, the costs of children, the extent of poverty, and poverty thresholds necessitates an accounting for these economies of scale.

One difficulty with household economies of scale is that it can be difficult to estimate the size of the scale economy, and household economies of scale are not as well defined as scale economies in production. While economies of scale are a function of the size of the household, the demand for goods and services generally derives from both household size and composition. When researchers turned their attention to economies of scale in the household, they overcame the problem of detection and measurement by concentrating on adult-only households, as in Nelson (1988). Measuring economies of scale for households where all members are the same type, have identical tastes, and are treated equally will not aid in the measurement of poverty, the distribution of income, and the costs of children, where compositional heterogeneity matters.

A second difficulty lies in the income and substitution effects that scale economies have on private goods. While both the income and substitution effects imply increased consumption of public goods, the income and substitution effects work in opposite directions for private goods, and it is not possible to know which effect will dominate unless we know more about the private good. Private goods which have low own- and cross price elasticities and sizable income elasticities are goods whose consumption is likely to increase with household size. The increased consumption of those private goods could be taken as a measure of household economies of scale, where larger 
households are better off in terms of private consumption due to scale economies in public consumption. Using this insight, Deaton and Paxson (1998) suggested that food would be a good choice for a private good where the income effect will dominate because food has few substitutes, and they argue that substitution away from food will be less likely for households close to subsistence. This implies that food expenditures should increase with household size- the savings realized on public goods would be funneled to food, a necessity which has few substitutes. Rather than increasing with household size, Deaton and Paxson found that food expenditure per capita decreases with household size. After considering and dismissing a number of possible explanations, they conclude that their empirical results are a puzzle.

A literature analyzing this "food puzzle" has developed (Gardes and Starzec 2000, Perali 2001, Horowitz 2002, Gibson 2002, Gan and Vernon 2003, Deaton and Paxson 2003, Vernon 2005, Gibson and Kim 2007), but research on household scale economies has yet to look at how or if scale economies change over time. Just as knowledge about scale economies at a point in time allows us to estimate the extent of poverty and inequality, knowledge about changes in scale economies are useful for analyzing changes in living standards over time. Even more, knowledge about change in scale economies is important since average household size has changed over time. Indeed, Pistaferri, et. al. (2005) use the concept of substitution between public and private goods to explain declines in household size over time. If the effect of household size on demand changes along with average household size we would need to know the extent of both to accurately measure trade-offs between public and private goods in the household. Lastly, time series information on economies of scale could allow us to resolve puzzles in the literature by eliminating potential explanations for the "food puzzle" and providing evidence of trends in economies of scale more generally. With these ideas in mind, this paper has two related goals: (1) To estimate household economies of scale in the American past to see how they have changed over time. This paper provides the first comparable historical estimates of household economies of scale. (2) To use estimates of economies of scale in the past to analyze the empirical "puzzles" in the literature- seeing which expenditure categories are consistent with theoretical predictions over time and which are not.

Using historical household surveys from the United States, covering the period 1888 to 1935, I estimate household scale economies for food, clothing, entertainment and housing. Scale economies in food show that the "food puzzle" holds for the past as well. In fact, I find that households 
in the past had fewer scale economies in food than today, exactly the opposite of what theory predicts. This finding deepens the "food puzzle" and cast serious doubt on whether food should be considered a private good for the measurement of household economies of scale. Furthermore, I find that existing explanations for the "food puzzle" do not explain the historical results. The other expenditure categories, however, are consistent with theoretical predictions, although they too vary over time. Scale economies in clothing declined over the period considered, and are the same in 1990 as they were in 1935. Scale economies in entertainment also fell from 1888 to 1935. Housing expenditures decreased significantly for larger households in 1888, but by 1935 household size had a substantially smaller effect on housing expenditures.

The paper unfolds as follows. The next section summarizes the theoretical model and highlights the empirical predictions about household scale economies in the past and over time. The third section outlines the empirical methodology. The fourth section presents estimates of scale economies in the household. The fifth section discusses the results in light of the "food puzzle" described above. The sixth section concludes.

\section{Measuring Household Economies of Scale}

There are two popular methods in the literature for measuring economies of scale in the household. The oldest and best known is the Engel method, while recent literature uses the Barten model to measure economies of scale. The Engel method has been preferred since it is easy to compute, but, as will be shown below, the Barten model is the superior approach for generating theoretical predictions about economies of scale in the household. Below, I review both methods, show why the Barten model will be employed here, and highlight the theoretical predictions about household economies of scale.

\subsection{Engel Measures of Household Economies of Scale}

In Engel measures of economies of scale the scale economy is simply the difference in per capita expenditures between two households (the per capita expenditure of the smaller household minus that of the larger household) who devote the same share of total expenditure to food. Following Engel's Second Law, two households with identical budget shares devoted to food are equally well 
off if the foodshare is an indicator of the standard of living. Taking $w$ to be food's share of the budget, $x$ as total expenditure, and $n$ as household size, the Engel method uses $\left(\frac{x}{n}\right)_{\overline{w_{k}}}-\left(\frac{x}{n}\right)_{\overline{w_{j}}}$, where $\overline{w_{i}}=w\left(\frac{x}{n_{i}}, n_{i}\right), j>k$ and $\overline{w_{k}}=\overline{w_{j}}$. Figure 1 gives a graphical description of the Engel method. This method almost always gives positive values for scale economies- larger households have lower per capita expenditures.

The Engel method implies, however, that the larger household has lower per capita food expenditures than the smaller household. At a constant budget share of food, lower per capita expenditures by the larger household imply lower per capita food expenditures for the larger household as well since $\left(\frac{x}{n}\right) \overline{w_{k}}>\left(\frac{x}{n}\right) \overline{w_{j}}$. This assumption disagrees, directly, with the notion that there are economies of scale in the household since expenditure on the private good (food) is lower for larger households. The Engel method does not give us theoretical justification for its measure of economies of scale, or show us how this measure is related to scale economies in the household in a tractable way. As such, we cannot use the Engel method to estimate economies of scale in the household since it is not a theoretically grounded measure of scale economies. ${ }^{1}$

\subsection{The Barten Model}

The Barten model, developed first by Barten (1964) and extended to the analysis of scale economies in the household by Muellbauer (1977), Pollak and Wales (1980, 1981), Deaton and Muellbauer (1986) and Nelson (1988), generates theoretical predictions about scale economies. ${ }^{2}$ As such, it has served as the model used by Deaton and Paxson (1998) and the basis for those who have attempted to resolve the puzzle they discovered and others more generally concerned with public and private goods in the household (Gardes and Starzec 2000, Perali 2001, Horowitz 2002, Gibson 2002, Gan and Vernon 2003, Deaton and Paxson 2003, Pistaferri, et al. 2005, Vernon 2005, Gibson and Kim 2007). In the two good Barten model a household of size $n$ allocates expenditure on two goods. For convenience, one good is completely private, $f$ (food), and the other is completely public, $h$

\footnotetext{
${ }^{1}$ Nicholson (1976) has shown that Engel's method cannot be used to calculate child equivalence scales and Deaton (1997) notes deeper theoretical problems with the Engel methodology, but Perali (2001, 2002) argues that the puzzle is a problem of functional form. He concedes, however, that more theoretical research on household economies of scale is needed because "the literature on household economies of scale is not fully developed in the sense that the concept of economies of scale in the household does not have a close analog to the traditional concept defined in production theory." (2001, p. 19).

${ }^{2}$ Although the literature deals with household economies of scale, the primary goal of that literature was the creation of equivalence scales that were consistent with utility theory (see, for example, Gorman 1976, Deaton and Muellbauer 1980, Pollack and Wales 1981, Lewbel 1985, Blundell, et. al. 2003).
} 
(housing). The household maximizes the utility function

$$
\max _{q_{f}, q_{h}} n v\left(\frac{q_{f}}{\phi_{f}(n)}, \frac{q_{h}}{\phi_{h}(n)}\right)
$$

where $v($.$) is the utility function, q_{f}$ and $q_{h}$ are the quantities of food and housing respectively, and $\phi_{f}(n)$ and $\phi_{h}(n)$ are scaling functions for the economies of scale realized for food and housing respectively. The scaling function converts the size of the household $(n)$ to its effective unit for both housing and food. In per capita terms the household budget constraint is

$$
p_{f}\left(\frac{q_{f}}{n}\right)+\left(\frac{p_{h}}{n}\right) q_{h}=\frac{x}{n}
$$

Maximization of the utility function subject to the budget constraint gives a per capita demand function for food

$$
\frac{q_{f}}{n}=\frac{\phi_{f}(n)}{n} g_{f}\left(\frac{x}{n}, \frac{p_{f} \phi_{f}(n)}{n}, \frac{p_{h} \phi_{h}(n)}{n}\right)
$$

where $g_{f}(\cdot)$ is the per capita demand function for food. Per capita expenditure on food is

$$
\frac{p_{f} q_{f}}{n}=\frac{p_{f} \phi_{f}(n)}{n} g_{f}\left(\frac{x}{n}, \frac{p_{f} \phi_{f}(n)}{n}, \frac{p_{h} \phi_{h}(n)}{n}\right)
$$

What we would like to know is how much per capita food expenditure changes for a given increase in household size. Taking logs of equation (1) above and then taking the derivative with respect to household size yields

$$
\frac{\partial \ln \left(p_{f} q_{f} / n\right)}{\partial \ln (n)}=\left[1-\frac{\partial \ln \phi_{h}(n)}{\partial \ln (n)}\right]\left(\epsilon_{f x}+\epsilon_{f f}\right)-\left[1-\frac{\partial \ln \phi_{f}(n)}{\partial \ln (n)}\right]\left(1+\epsilon_{f f}\right)
$$

where $\epsilon_{f f}$ is the own price elasticity of food and $\epsilon_{f x}$ is the income elasticity of food. ${ }^{3}$ In order for per capita food expenditure to increase with household size it must hold that

$$
\left[1-\frac{\partial \ln \phi_{h}(n)}{\partial \ln (n)}\right]\left(\epsilon_{f x}+\epsilon_{f f}\right)>\left[1-\frac{\partial \ln \phi_{f}(n)}{\partial \ln (n)}\right]\left(1+\epsilon_{f f}\right)
$$

\footnotetext{
${ }^{3}$ Note that if a good is purely public that $\left[1-\frac{\partial \ln \phi_{i}(n)}{\partial \ln (n)}\right]=1$ because there would be no change in effective household size for an increase in actual household size. If a good is purely private then $\left[1-\frac{\partial \ln \phi_{i}(n)}{\partial \ln (n)}\right]=0$ because effective household size would change exactly as much as actual household size.
} 
When food has few substitutes, meaning that $\epsilon_{f f}$ is small in absolute value, and if food has fewer scale economies than housing, meaning that $\left[1-\frac{\partial \ln \phi_{h}(n)}{\partial \ln (n)}\right]>\left[1-\frac{\partial \ln \phi_{f}(n)}{\partial \ln (n)}\right]$, then we would expect the derivative given in (2) to be greater than zero. ${ }^{4}$ This is essentially asserting that the savings obtained by economizing on the public good are used to increase consumption of the private good, where the income effect dominates the substitution effect for the private good because there are few substitutes for it. In this way, the Barten model gives us theoretical grounds upon which we can hypothesize about when, where, and for what goods we would expect economies of scale to be present.

To summarize, the Barten model predicts that:

- Holding per capita expenditure constant, the share of the budget devoted to the private good will increase with household size if it has few substitutes and a sizable income elasticity.

- If poorer households have fewer substitutes for expenditures on the private good, such that $\epsilon_{f f}$ is relatively smaller for poorer households, the increase in expenditures on the private good will be greatest for the poor.

- Over time, as the market expands and more substitutes for expenditure on particular private goods are available, $\epsilon_{f f}$ will increase and economies of scale in a particular private good should decrease.

The Barten model also has implications for public goods and their scale economies over time:

- Holding per capita expenditure constant, the share of the budget devoted to the public good will decrease with household size. This would be the source of cost savings funneled towards private goods- the basis of household economies of scale.

\subsection{Household Economies of Scale in the Past}

We can use our knowledge of the past to generate further predictions about economies of scale and how we believe they would change over time. While we know that the predictions of the Barten

\footnotetext{
${ }^{4}$ Another way to rewite the inequality is $\frac{\left(\epsilon_{f x}+\epsilon_{f f}\right)}{\left(1+\epsilon_{f f}\right)}>\frac{\left[1-\frac{\partial \ln \phi_{f}(n)}{\partial \ln (n)}\right]}{\left[1-\frac{\partial \ln \phi_{h}(n)}{\partial \ln (n)}\right]}$. When the income elasticity of the private good is high (approaching unity) a private good that is only slightly more private than the public good will suffice for the condition to hold. The food elasticities reported in Logan (2006) are above .8 in the late nineteenth century US.
} 
model have been rejected for food in contemporary populations, there are several reasons to believe that the model should hold for food and other private goods in the past. Historically there were fewer substitutes for food, and it was not possible to substitute food preparation for expenditure to the extent that it is today. ${ }^{5}$ As such, it is reasonable to expect $\epsilon_{f f}$ to be particularly small in the past. Similarly, the demand for food in the past was greater than it is today. Logan (2006) estimates food income elasticities above 0.8 for the United States in the late nineteenth century. If the income elasticity of food was very large in the past it would be even more likely that food expenditure would increase with household size. All of this implies that we should expect for food to behave in a manner consistent with the Barten model in the past- holding per capita expenditure constant food expenditure should increase with household size.

Furthermore, food is not the only private good that can be tested against the predictions of the Barten model. It is therefore useful to estimate economies of scale for other household expenditure categories. Clothing and entertainment expenditures have each been considered private goods in the literature, although the degree to which each is private is subject to debate. Similarly, the Barten model has implications for public goods, and this can be tested by looking at housing expenditures to see if they are consistent with the predictions of the Barten model. In short, we can estimate economies of scale in the past for a number of different goods and see if the time trends would be consistent with the predictions of the Barten model for both public and private goods.

I estimate economies of scale with American household survey data covering 1888 to 1935. The survey data used here comes from three national consumer expenditure surveys taken in 1888-1890, 1917-1919, and 1935-1936. ${ }^{6}$ For each survey, I estimate the scale economies of food, clothing, entertainment, and housing. Each survey is a large national survey of consumer expenditures and these surveys are comparable insofar as they each detail household expenditures, income, and household composition. Similarly, each survey used a similar methodology, interviewing subjects in their homes, verifying expenditures where possible, and using consistent categories for goods. ${ }^{7}$

\footnotetext{
${ }^{5}$ See Byington (1910), Cowan (1983) and Moykr (2000) for more on historical substitution between food expenditures and time preparation and Aguiar and Hurst (2005, 2006) and Vernon (2005) for more on contemporary substitution.

${ }^{6}$ The surveys are the Department of Labor's Cost of Living of Industrial Workers in the United States and Europe (1888-1890), the Bureau of Labor Statistics' Cost of Living in the United States (1917-1919), and the Department of Labor's and Department of Agriculture's Study of Consumer Purchases in the United States (1935-1936).

${ }^{7}$ See the data appendix for more information on the data sources, including survey construction and summary
} 
In addition, each survey has comprehensive demographic information on all household members, which allows us to measure the effect of household size separate from the effects of household composition. Because these surveys are broadly consistent over time, it is possible to derive time trends in household scale economies from them.

\section{Empirical Strategy}

Our empirical task is to determine if food expenditure per capita increases with household size, holding per capita expenditure constant. The hypothesis is that

$$
E\left(\frac{p_{f} q_{f}}{n_{j}} \mid j, \frac{x}{n}\right)>E\left(\frac{p_{f} q_{f}}{n_{k}} \mid k, \frac{x}{n}\right)
$$

where $j>k$. Since we are conditioning on per capita expenditure, we can use the share of the budget devoted to food, $w_{f}$, since $w_{f} \equiv \frac{p_{f} q_{f}}{x}=\frac{\frac{p_{f} q_{f}}{n}}{\frac{x}{n}}$. In other words, at the same level of per capita expenditures, households that devote a larger share of their budget to food have larger per capita food expenditures by definition. This simplifies the task to estimating the Engel curve for each type of expenditure and testing whether the budgetshare increases with household size. An additional strength of using the Engel curve is that we can estimate the demand for the goods using a variant of the Almost Ideal Demand System (AIDS). In each survey, I take total annual expenditures on food, clothing, entertainment and housing and divide each separately by total annual household expenditure as the dependent variables (the budget shares). Following the previous literature, I estimate economies of scale in four ways for robustness. Three of the methods allow for increasing flexibility of the Engel curve, and the fourth method addresses the problems of the endogeneity of the budget share with per capita expenditure. ${ }^{8}$ I detail each estimation procedure below.

1. Linear (Ordinary Least Squares)- The first method estimates economies of scale with a linear Engel curve using ordinary least squares (OLS). This specification attempts to separate the

statistics. See Costa (2001) for more on the comparability of the 1888, 1917, and 1935 surveys. Due to the lack of comparability with later consumer expenditure surveys, this paper concentrates on the oldest suverys.

${ }^{8}$ For comparability parametric estimates are needed. Congruent with the previous literature, I assume that household size has a level effect on demand. Nonparametric tests of this assumption with historical survey data (as in Logan 2006) have shown that it is valid. See Deaton and Paxson (1998) for more on non-parametric analyis of household economies of scale, and Blundell, et. al. (2003) for more on the closely related topic of non-parametric equivalence scales. 
effect of household size from household composition on the budget share. The regression takes the form

$$
w=\alpha+\beta \ln \left(\frac{x}{n}\right)+\gamma \ln n+\sum_{k=1}^{K-1} \delta_{k}\left(\frac{n_{k}}{n}\right)+\zeta z+\varepsilon
$$

where $w$ is the budget share, $x$ is total expenditure, $n$ is household size, $k$ is a grouping of the household by age and sex (such that $n_{k} / n$ is the fraction of the household belonging to demographic group $k$ ), and $z$ is a vector of control variables including the fraction of the household that is employed, geographic (state) controls, and the industry that employs the head of the household. ${ }^{9}$ The composition of the household is broken into 5-year age-sex categories up to the age of 25. The measure of economies of scale is $\gamma$, the effect of household size on demand. ${ }^{10}$

2. Fourier Engel Curve- The second method uses a Fourier functional form of the Engel curve, giving it greater curvature and flexibility. This regression takes the form

$$
\begin{aligned}
& w=\alpha+\beta \ln \left(\frac{x}{n}\right)+\phi \ln \left(\frac{x}{n}\right)^{2}+\sum_{j=1}^{3}\left[\vartheta_{j} \sin \left[j \ln \left(\frac{x}{n}\right)\right]+\xi_{j} \cos \left[j \ln \left(\frac{x}{n}\right)\right]\right]+\gamma \ln n+\sum_{k=1}^{K-1} \delta_{k}\left(\frac{n_{k}}{n}\right)+ \\
& \zeta z+\varepsilon
\end{aligned}
$$

where once again the measure of economies of scale is $\gamma \cdot{ }^{11}$

3. First Differencing Method- The third method allows the Engel curve to take the form of any continuous function, giving it the greatest flexibility while still estimating the effect of household size on demand. Following the method proposed by Estes and Honore (1995) and Yatchew (1997) we can difference out the Engel function entirely if it is continuous and still obtain and unbiased (but not efficient) estimate of economies of scale. The differencing is achieved by sorting the data by per capita expenditure and taking first differences such that $\Delta x=\left(x_{(i)}-x_{(i-1)}\right)$. Note that if the Engel function is continuous and the sample sufficiently large, sorting by per capita expenditure implies that $\Delta f\left(\ln \frac{x}{n}\right) \rightarrow 0$, such that it

\footnotetext{
${ }^{9}$ As relative prices are fixed, the geographic controls would caputure the effect of differences in relative prices across space.

${ }^{10}$ Formally, estimates of the economy of scale would regress the log of the budgetshare on the log of per capita expenditure and household size, which would be consistent with the theory described earlier. Since the log of the budget share is simply a monotonic transformation of the budget share itself, all of the estimates here are qualitatively similar.

${ }^{11}$ In this analysis the range of the variable in the Fourier analysis must be less than $2 \pi$, or it must be rescaled. All of the per capita expenditure ranges considered in this paper have a range of less than $2 \pi$, and therefore do not need to be rescaled.
} 
can be omitted from the regression. The regression is

$$
\Delta w=\alpha+\gamma \Delta \ln n+\sum_{k=1}^{K-1} \delta_{k} \Delta\left(\frac{n_{k}}{n}\right)+\zeta \Delta z+\nu
$$

The measure of economies of scale is $\gamma$. This method should yield estimates of economies of scale similar to those in the OLS and Fourier models. Suppose that one wished to estimate a non-parametric $[g(*)]$ Engel curve of the form

$$
w=g(\ln x)+\varepsilon
$$

If one would like to control for the linear demographic effects $z$, we would want to estimate a partially linear model of the form

$$
w=g(\ln x)+\varsigma z+\varepsilon
$$

The additive structure of the equation above and the Slutsky symmetry conditions requires that $g(\ln x)$ be linear (see Blundell, Browning, and Crawford (2003) for a proof). Indeed, one method for having $g(*)$ not enter linearly would be to deflate $\ln x$ by a general household equivalence scale, which itself depends on estimates of household scale economies to the extent that additional persons in the household share public goods. For this reason, we would expect the semiparametric method to yield results similar to those of the OLS and Fourier specifications.

4. Instrumental Variables- The fourth method addresses the fact that budget shares and per capita expenditures are constructed from the same information and the errors of both may be correlated as well, which would lead to biased estimates of $\beta$. Also, since per capita expenditure and household size are also correlated, such errors would also lead to biased estimates of $\gamma$, the coefficient of interest. ${ }^{12}$ Even more, we do not know, a priori, which direction the bias would be in. Income, which is highly correlated with expenditures but measured independently of it, is a good candidate as an instrument for per capita expenditure. The instrumental (IV) estimates use the log of per capita income as an instrument for the log of per capita expenditure.

\footnotetext{
${ }^{12}$ See Gibson (2002) and Gibson and Kim (2007) for more on correlated measurement error with respect to the "food puzzle."
} 


\section{Estimates of Household Economies of Scale}

In this section, I present estimates of household scale economies for food, clothing, entertainment and housing from 1888 to 1935. Testing another prediction of the Barten model, that poorer households should increase their expenditure on private goods more than wealthier households, I estimate economies of scale by income quartile over time. I then consider possible explanations of the "food puzzle," and show that the results for food are inconsistent with both theory and the potential solutions to the "food puzzle".

\subsection{Scale Economies in Food}

Table 1 shows estimates of the scale economy of food estimated in 1888, 1917, and 1935. The coefficients in the table show the effect of household size on the budget share devoted to food $(\gamma)$ for each estimation method. ${ }^{13}$ For example, linear (OLS) estimates show that if household size were doubled in 1888 , the share of the food budget share would decrease by roughly $2.3 \% .{ }^{14}$ There are several items of interest in Table 1. First, the four estimation methods yield remarkably similar estimates of the scale economy with respect to food. Second, all of the estimates of the food scale economy are negative. Regardless of the year, the food share never increases with household size. This mirrors the result found in Deaton and Paxson, but the results in Table 1 deepen the puzzle to the extent that, in the past, the conditions under which food expenditures should increase with household size were stronger in the past. There were fewer substitutes for food expenditures than there are today and the income elasticity of food was high in the past. The failure of household size to be positively correlated with food expenditures in the past is truly a puzzle.

Even more troubling, there is no clear time trend from the estimates of the scale economy with food, a further contradiction of the Barten model. The scale economy is least private in 1917, and closest to zero in 1888. The increase in the size and scope of the market should lead to greater substitutes for food, and the increasing number of substitutes should lead the scale economy to decrease over time, ceteris paribus. Although the scale economy does decrease from 1888 to 1917, it increases from 1917 to 1935. It is unclear what movements could be behind such a pattern.

\footnotetext{
${ }^{13} \mathrm{It}$ is important to note that the estimates here are not estimates of the scaling parameter in the model, $\phi_{f}$, but the effect of household size on demand. For more on problems with estimating the scaling parameter directly see Deaton (1997) and Deaton and Paxson (1998).

${ }^{14}$ More precisely, the effect of doubling household size would be $\gamma * \ln (2)$ (where $\left.\ln (2)=.693\right)$.
} 
As a further check of robustness, we can look at food consumption at and away from home. This information is not available in the 1888 survey, but it is detailed in the 1917 and 1935 surveys. Although meals out of the home were infrequent in the past, it is still possible that the negative coefficient on household size seen in Table 1 could reflect the fact that larger families consume fewer meals out of the home. If that was true, larger households would have lower food expenditures since meals out of the home are usually more expensive than those consumed in the home. Economies of scale in food preparation would induce larger households to substitute towards home-produced meals in the past, and Vernon (2005) has suggested that this should hold for the present. Indeed, Aguiar and Hurst $(2005,2006)$ suggest that expenditures on food for households with large time endowments should be lower than households with smaller time endowments. Since meals outside of the home are costly, and do not take advantage of the time economy of scale in household production, households with large time endowments should have lower expenditures on meals outside of the home, holding per capita expenditure constant. Table 2 shows the coefficients on the log of family size for regressions on food at and away from home. Food expenditures away from home increase with family size, and over time the effect grows larger. Food expenditures at home decrease with household size, and the trend from 1917 to 1935 is the same as it is for food expenditures in general. Meals away from home cannot explain the results in Table $1 .{ }^{15}$

The ultimate conclusions drawn from the scale economy of food are that it does not behave in the way that a private good consistent with the Barten model would and it does not have a clear time trend consistent with the Barten model. While we will consider the implications of this later, we can also compare these historical estimates of the scale economy to contemporary estimates. Deaton and Paxson's estimate for 1990 from the Consumer Expenditure Survey, .008 , is significantly lower than any of the historical estimates for the economies of scale in food consumption in Table 1. This further deepens the puzzle insofar as the scale economy in the past should be positive, yet empirically the historical estimates are all more negative than the contemporary estimates, where the conditions of the Barten model are more likely to hold.

\footnotetext{
${ }^{15}$ The results in Table 2 also contradict Gan and Vernon's (2003) finding that IV estimates for household size's effect on food expenditures out of the home are negative- each method here yields positive estimates.
} 


\subsection{Scale Economies in Clothing}

A priori, clothing is a private good, and we would expect clothing expenditures to increase with household size. Table 3 shows estimates of the scale economy with respect to clothing expenditures. As with the estimates of the food scale economy, the estimation techniques yield similar estimates of the scale economy. Unlike the food scale economy, however, the clothing scale economy is always positive, consistent with the prediction for private goods in the Barten model. Increases in household size lead to increased clothing expenditure per capita.

The scale economy of clothing, like the scale economy of food, changes over time. Furthermore, the trend in the clothing scale economies is consistent with the predictions of the Barten model. As the market develops and there are more substitutes in the market for expenditures on the private good, the size of the scale economy should diminish over time, and this is exactly what happens with the scale economy of clothing. ${ }^{16}$ The scale economy is 1888 is approximately $70 \%$ greater than the scale economy measured in 1917, and the scale economy in 1917 is approximately $40 \%$ larger than the scale economy measured in 1935. These differences are statistically significant. The conclusion from the clothing scale economy is that clothing appears to be a private good that behaves in a way that is consistent with the Barten model.

The clothing scale economy is also consistent with the Barten model over the twentieth century. The scale economy in clothing in 1990 was .0194. The estimate for 1935 is close to that range, but slightly higher. If the scale economy declined consistently over time, the effect of household size would have decreased by .00084 per year from 1888 to 1935, while it would have declined .00018 per year from 1935 to 1990 . This suggest that scale economies in clothing decreased at a decreasing rate from 1888 to 1990 . Such a trend is entirely consistent with the notion that the most likely substitutes for clothing appeared on the market between 1888 and 1935.

\footnotetext{
${ }^{16}$ This could also be due to the real price of clothing declining over time, such that households devote expenditure on other private goods, or goods being placed on the market that substitute for home production, although these are not the only possibilities. Expansion of the market generally is difficult to quantify, especially during this time period. Adding to these complications is that fact that the consumer durables revolution also saw an expansion of advertising/catalogs and the use of consumer credit- both of which can expand the market for goods by providing consumers with more information and by lowering the short-run cost of ownership. For more on the economic history of this time, particularly the role of consumer credit, advertising, and the catalog revolution, see Olney (1991).
} 


\subsection{Scale Economies in Entertainment}

Expenditures for entertainment may be private, if they are enjoyed by a certain segment of the household. The estimates of the scale economy in entertainment are consistent with entertainment behaving as if it were a private good. Table 4 shows the results. The economy of scale estimates for entertainment are positive for every year considered. As with food and clothing, the estimates for entertainment's scale economy change from year to year, and these differences are statistically significant. From the OLS results, the scale economy estimate in 1888 is $75 \%$ larger than the 1917 estimate, and the 1935 estimate is approximately 25\% larger than the 1917 estimate.

As with food, the entertainment scale economy does not follow any particular time trend. The estimates in 1888 are the largest, and the 1935 estimates are larger than the 1917 estimates. So although entertainment appears to be a private good in the Barten model sense, it does not behave with any clear time trend as predicted by the Barten model. Overall, however, the changes in the entertainment economies of scale, while statistically significant, are not very different qualitativelydoubling household size would not increase entertainment's share of the budget by $1 \%$, and usually less than half of that. This may be due to the fact that what comprises entertainment changes from survey to survey, and of all the expenditure categories considered it is the most difficult one to construct a time consistent estimate for. ${ }^{17}$

The size of the scale economy in entertainment in 1990 was .0087, which is larger than nearly any of the historical estimates, and suggests that entertainment has become an increasingly private good over time. This would be consistent with the growth of the entertainment industry in general, and the increasing segmentation of the entertainment industry over time. Part of the decrease in the scale economy in entertainment from 1888 to 1917 could be due to the rapid increase of entertainment products on the market during that time, particularly movies, radio, and recorded music, many of which were marketed to the family as a whole (Olney 1991). The increasing scale economies since 1917 would be consistent with specialized, and therefore more likely private, entertainment options from the 1920s to today.

\footnotetext{
${ }^{17}$ See the appendix for more on the expenditures that comprise entertainment in each survey. Due to the difficulty of constructing a time-invariant measure of entertainment, and the expansion of entertainment and leisure options on the market during this time period, it is not clear how to interpret the lack of a trend in the entertainment scale economy. For more on the difficulties of capturing a time consistent measure of entertainment see Costa (1999).
} 


\subsection{Scale Economies in Housing}

Housing is a public good. As such, the estimates of scale economies for housing should be negative if housing is consistent with the Barten model. This is a check to see if the Barten model's predictions are consistent with a good on the other side of the public/private divide. A priori, changes in scale economies for the public good would lead to changes in economies of scale for the private good. Table 5 shows the scale economies in housing to be consistent with the Barten model. In every year, increases in household size are correlated with decreases in the share of expenditure devoted to housing. As with the other expenditure categories, the scale economy in housing does change over time. As Table 5 shows, the scale economy estimate in 1888 is substantially larger than the 1917 estimate (in absolute value), and the 1917 estimate is more than twice the size of the 1935 estimate (in absolute value). ${ }^{18}$ In fact, the changes over time in scale economies are most dramatic for housing. As with the other expenditure items, these differences are statistically significant.

Estimates for the scale economy in housing for 1990 was -.0532 , which is larger than the 1935 value of the scale economy. A natural explanation for this reversal would be the increasing ease of home ownership, particularly with the advent of government insured mortgages in the United States. As is well known, these sorts of public policies led to a general expansion of the housing market. All of this serves to decrease the cost of home ownership, and the income effect for this public good would be large as a result. This decrease in the cost of home ownership most likely outweighs the increasing number of substitutes to housing in the market, explaining the reversal of the trend. Improvements in the availability and performance of functions inside of the household such as heating, cooling, furniture, bedding, and appliances would also have a strong impact on the presence of household scale economies for housing. ${ }^{19}$

\footnotetext{
${ }^{18}$ The IV estimate for housing in 1888 is positive while all other methods give negative estimates. Income is not likely to be a good instrument for expenditure on housing in the 1888 survey. A non-negligible number of households in the 1888 survey lived in "company houses" that were furnished by their employers. Inclusion of household furniture and appliances with housing expenditures, which would not be subject to some of the same problems as housing expenditures only, results in much lower (less positive) IV estimates (from .787 to .072), while the other methodologies are not similarly effected to this magnitude. Since previous debates surrounding household economies of scale have centered on differences in point estimates when using different methodologies, I present all estimates for each survey.

${ }^{19}$ When furniture and appliances are added to the estimates of housing the results are less negative than for housing alone (for all but the IV results). This result is consistent with these other goods acting as substitutes for housing expenditure.
} 


\subsection{Scale Economies and the Income Distribution}

There is an additional robustness check that can be performed on the scale economies considered above, and acts as an additional test of the Barten model. The scale economy should also change as a function of income, regardless of the year in which it is measured. The Barten model predicts that if poorer households have fewer substitutes for the private good they will increase consumption of the private good more than wealthier households. To test this prediction, I estimated the size of the scale economy for each expenditure category by income quartile for each survey year.

Since food in general is not consistent with the Barten model, it is not clear how it should behave as a function of income. If the general property that poor households have smaller own price elasticities for food than wealthier households holds, then poorer households should have less negative estimates of scale economies in food than wealthier households. Table 6 shows this to be the case in every survey. Households in the first income quartile have household scale economies in food that are greater than the scale economies of households in the fourth income quartile. For clothing, the results are broadly consistent with the Barten model. In general, households in the first income quartile would increase their expenditures on clothing more than households in the fourth income quartile. With the general pattern of declining scale economies in clothing over time, however, the differences narrow, and by 1935 there are not statistically significant differences in the size of the clothing scale economy by income quartile.

In contrast to these findings, poorer households have the lowest increase in expenditures for entertainment with household size. This would be entirely consistent with entertainment being a luxury that poor households can ill afford, or poorer households choosing more public versions of entertainment. Housing expenditures, however, are more nuanced. While the 1888 results are consistent with poorer households having the largest scale economies in housing, the 1917 and 1935 results suggest that wealthy households have the largest scale economies in housing. This could be due to poorer households having larger own price elasticities for housing, and large cross price elasticities for items such as furniture, bedding, appliances, and the like, which is entirely likely to hold if housing prices are high. ${ }^{20}$ The results do show, however, that for the same income quartile,

\footnotetext{
${ }^{20}$ Just as the effect of household size on demand was less negative when furniture and other presumably public goods were included, the income dictribution results with this expanded definition of housing do show some greater stratification by income quartile.
} 
the scale economy in housing decreases over time. Overall, the income distribution results are broadly consistent with the predictions of the Barten model, such that the cross-section predictions about scale economies and the income distribution are supported by the data in nearly every case. Even conditioning on quartile of the income distribution, there is a large change in the scale economies over time.

\section{Does the Past Help us Resolve the "Food Puzzle"?}

To see if the past helps us resolve the "food puzzle" we should first see if the solutions offered by others hold for the past. In particular, for certain explanations of the "food puzzle" to hold the scale economies in food should display a specific time trend. If direct economies of scale in food cause the per unit price of food to be lower in larger households this effect should intensify over time as technology allows larger households to purchase and store large quantities of food, which are sold at cheaper prices in bulk. Since the effect of household size on demand is stronger in the past, however, such an explanation is unlikely to resolve the issue. Also, if income is distributed unequally within the household (where larger households have more unequal distributions than smaller households) food consumption could decline with household size and explain the "food puzzle." ${ }^{21}$ If the Engel curve is relatively stable over time, however, the effect should attenuate and the scale economies in food should increase over time. While in general the effect does lessen over time, it does not do so in a consistent fashion (as it does for clothing). Overall, the evidence is not wholly consistent with an inequality explanation.

There are additional tests of the "food puzzle" that other researchers have used to investigate (and potentially resolve) the puzzle. Gan and Vernon (2003) argued that the "food puzzle" resulted from improper specification of the predictions of the Barten model. In the two good model presented in this paper, food must be more private than housing for food expenditure per capita to increase with household size $\left(\right.$ where $\left.\left[1-\frac{\partial \ln \phi_{h}(n)}{\partial \ln (n)}\right]>\left[1-\frac{\partial \ln \phi_{f}(n)}{\partial \ln (n)}\right]\right)$. Gan and Vernon argue that the generalization of this condition to a world with more than two goods would require food to be more private than all other expenditures, not only housing. They argue that all other goods, $\left(1-w_{f}\right)$, will contain expenditure categories that are more public than food and others that

\footnotetext{
${ }^{21}$ This also requires that the Engel curve be concave. Non-parametric estimates of the Engel reveal that the function is indeed concave in each of the historical surveys analyzed here.
} 
are more private than food. Rather than testing to see if the foodshare increases with household size, they argue that food should be paired with other goods known to be more private than food so that the composite good (in their case food and clothing) will be more likely to be more private than all other household expenditures. They assert that such a test is closer to the predictions of the Barten model. In their paper they pair food and clothing expenditures and find that the food and clothing share is positively related to household size for their contemporary household surveys, and consistent with the idea that food and clothing are jointly private goods. ${ }^{22}$ Unfortunately, the results do not hold for the historical household surveys used in this paper. Table 7 shows the results, where the food and clothing share is negative in 1917 and in 1935. This implies that the negative correlation of household size and the foodshare dominates the positive relationship between household size and the clothing share.

Similarly, Gan and Vernon suggest that food should be tested directly against categories known to be more public than food, such as housing. They find that the share of food in food and shelter, $\left(\frac{f}{f+h}\right)$, is positively related to household size in their contemporary household surveys. ${ }^{23}$ They take this as evidence that food is more private that housing, which they argue is in agreement with the predictions of the Barten model. Table 7 shows that this was not always the case- food in food and housing was negatively related to household size in the past. Given these results, Gan and Vernon's attempts to resolve the puzzle by grouping food with other items and comparing food to other goods assumed to be more public or private than food do not generate similar conclusions with historical evidence.

Since the Barten model's implications for food fail to hold in the past, when food expenditure was even more likely to increase with household size, we are left to uncover the reasons why food in particular does not fit to the predictions of the model. To begin, consider the Engel function $w\left(\frac{x}{n}, n\right)$ where $w$ is the share of the budget devoted to food, $x$ is expenditure, and $n$ is the size of the household. We know from Engel's first law that $\frac{\partial w}{\partial \frac{x}{n}}<0$ and empirically the results of Table 1 confirm that $\frac{\partial w}{\partial n}<0$. These two derivatives tell us that the share of the budget devoted to food is decreasing both in per capita expenditure and in household size. Figure 1 displays this.

\footnotetext{
${ }^{22}$ Their surveys come from the United States (1990 Consumer Expenditure Survey), South Africa (1993 Living Standards Survey), and Russia (1994-1998 Russian Longitudinal Monitoring Survey).

${ }^{23}$ As Gan and Vernon note, analyzing the share of food in food and housing requires that utility be separable with respect to food and housing and assumes that the household optimally allocates expenditures between food and housing and all other items.
} 
Engel measures of economies of scale, which were rejected earlier because of their lack of theoretical justification, use these two facts to derive estimates of economies of scale. Indeed, if $\frac{\partial w}{\partial n}<0$ and $\frac{\partial h}{\partial n}<0$ (where $h$ is the budget share devoted to housing), it must hold that $\frac{\partial[1-w-h]}{\partial n}>0$ and more generally that $\frac{\partial[1-w]}{\partial n}>0$ by Walras' law. This implies that food is indeed less private than everything else if the sign of the derivative is an indication of household economies of scale. While the finding that $\frac{\partial w}{\partial n}<0$ may present a theoretical puzzle in light of the Barten model, this has been a feature of Engel curves since their inception, and one of the reasons that Engel argued that larger households could be welfare-equated to smaller households with lower per capita expenditures. ${ }^{24}$ The true puzzle, it seems, is how such an assumption (or assertion) can be theoretically justified as being welfare equivalent. ${ }^{25}$

This puzzle seems to turn on the idea of welfare itself. What does it mean, empirically, to welfare equate households of different sizes? If welfare equivalence is similar proportional expenditures, it would seem as if the Barten model fails and the Engel conjecture survives, although what this measure actually is remains unclear. If welfare equivalence is taken to mean equating consumption, however, the problem is more complicated - a model describing the household production of food is needed. It will be difficult to specify a model that would accurately describe the changes in household technology over this time period. While Engel assumed (implicitly) that households with more members would spend less per capita on food, perhaps because other factors in the food production process increase with household size, more than conjecture will be needed to generate the sorts of predictions that the Barten model gave for changes in economies of scale as a function of technological change. ${ }^{26}$

A factor that is obviously related to food production is time. Since household time is increasing

\footnotetext{
${ }^{24}$ Consider a simple calorie production function $F(w x, O)$ where $F(*)$ is the calories available to the household and $O$ factors other than food purchases involved in the production of the food that lands on the plates from which we eat (time, cooking technology, food transportation and storing technology, etc.). Two households of different sizes are equally well off if $\frac{F(w x, O)}{n_{i}}=\frac{F(w x, O)}{n_{j}}$ where $n_{i} \neq n_{j}$. If the food production function is strictly increasing

in both arguments and the other factors of food production increases with household size, $\frac{\partial O}{\partial n}>0$, then household expenditure on food must decrease with household size for households of different sizes to be equally well off- if not, larger households would be strictly better off.

${ }^{25}$ Perali (2002) describes how the Engel procedure is an exact measure of welfare. The assumptions needed for this to hold (the equivalence scale must be price independent and independent of the base income level chosen for comparison) make the Engel method very restrictive.

${ }^{26}$ This has been argued in a similar context by Aguiar and Hurst (2005) and Gronau and Hamermesh (2006, 2007).
} 
in the size of the household, larger households can substitute time for expenditure on food while leaving food consumption unchanged. Aguiar and Hurst (2005, 2006) and Vernon (2005) have recently argued that anomalies similar to the "food puzzle" could be explained by time as an input into the food production function. The problem for the historical trends is that while there are models of time use in a household production function, time is not the only other factor that would be important during this time period- electrification, the availability of natural gas, household refrigeration, transportation innovations, changes in agricultural technology, knowledge and dissemination of sanitary food preparation techniques and other factors all play a role in the production of food at home from the middle of the nineteenth century onward. ${ }^{27}$ Even more, some factors would be complements to time input while others would be substitutes- not all technological change was labor saving for household production (Cowan 1983 and Moykr 2000). Pollack (1999) has argued that time-use data alone is insufficient to explain household technology, and Bowden and Offer (1994) have shown that time use and technology were not always substitutes. A question of whether the income or substitution effect dominates for food expenditure will be embedded in a question of whether the complements or substitutes to time input win out in a food production model at a particular point in time. As such, we would have more unknowns than we could accurately estimate, and it will be impossible to identify the model. ${ }^{28}$

While time as an input in the food production function may explain parts of the puzzle for contemporary populations, the market for prepared foods was small in the past, such that the extent of substitutability would not be as great in the past as it is today. All households had to

\footnotetext{
${ }^{27}$ It is important to note that all of the households in the surveys used here were urban and not employed in the agricultural sector. The changes in household production brought about by technology would obviously be different for agricultural households if their home production function was different (either fundamentally or in a matter of degrees) from the production function for urban, industrial households.

${ }^{28}$ While one could calibrate a model to describe this process, as Pistaferri, et. al. (2005) and Schoellman and Tertilt (2007) do, the plausibility of changing preferences, which would change the presumed substitution between public and private goods, presents additional problems to the calibration. Imagine, for example, that the substitution between public and private goods is a function of income. Over time, changes in household economies of scale could reflect movement along the substitution function (changes in income) and/or shifts of the function itself due to changes in preferences (perhaps preceeded by technological change or the spread of new information). Even with such complications, Pistaferri, et. al. use a variant of the Barten model and fit it to contemporary cosumer expenditure data (1980-2004) to show that growth in income explains a non-trivial portion of changes in household size from 1850 to 2000. The open questions are whether shifts of the substitution function itself would increase or decrease the role that income growth has played in changing average family size over time and whether calibrating the model with historical data would lead to different estimates of the substitution between public and private goods. The results of this paper suggest that using historical data would change the calibration results, and the technique would also be sensitive to the type of goods used to capture the public/private substitution.
} 
contribute significant time to food preparation in the past. ${ }^{29}$ The results of Table 2 confirm that large households did not substitute towards home produced meals. Additionally, Cowan (1983) has shown that time input in household production increased during the time period considered here, despite the advent of (presumably) labor saving technology in the household. ${ }^{30}$ This could be due to redundant use of both new and old technologies in household production. Furthermore, while time is certainly an input into the production of food, time was also an input in the production of goods like clothing in the past. ${ }^{31}$ Hours spent in household production would imply that "puzzles" would exist for other private goods in the past that have time as a significant input, or at least a case must be made for why food would be different from other time intensive processes. ${ }^{32}$ In general, empirical identification of the relevant factors from such models will be difficult given the historical data.

A further complication is that demand for certain types of household production may have changed significantly during this time period for reasons unrelated to changes in household technology. Moykr (2000) has argued that demand for cleanliness and sanitation of food increased as a result of knowledge of the germ theory of disease and the subsequent public health interventions and campaigns of the late nineteenth and early twentieth centuries. As such, demand for cleanliness and sanitation (including food preparation) changed, and this could explain the increased hours spent in household production. ${ }^{33}$ Similarly, technological changes like refrigeration would have changed food availability, which itself could change the time spent cooking and preparing food, although the

\footnotetext{
${ }^{29}$ See Byington (1910) and Logan (2005, 2006) for more on household production of food in the past.

${ }^{30}$ Greenwood, et. al. (2005) argue that technological change freed women from time spent on household chores, but Cowan (1983) notes that hours spent on household chores increased from 50 in the late nineteenth century to 56 in the early twentieth century, and only began to decline after WWII- well after the time period considered here. Bowden and Offer (1994) note that "The evidence...indicates no clear link between time-saving appliances and the time spent in housework. It suggests that the decline in housework followed the diffusion of the main household appliances by a considerable lag, and that a decline in housework time began only in the early 1960s." (p. 734, emphasis in original) The relationship between changes in household production technologies and time use is still a subject of debate in the literature.

${ }^{31}$ Smith (1994), for example, shows that clothing expenditures for mothers were inversely related to fertility, but for men they were invariant.

${ }^{32}$ If this were true it would have to hold that poorer households would use time to substitute for expenditure more than wealthier households- for example, the opportunity cost of time is lower for poorer households. (Also note, however, that consumption for households could not be equated without an inverse relationship between time input and income since expenditure increases with income.) As such, the results in Table 6 would have to show that expenditure on food and clothing would decrease with household size more for poorer households than wealthier households; Table 6 shows exactly the opposite.

${ }^{33}$ Bowden and Offer (1994) note that "Washing machines did not save time since clothes were washed more often. Vacuum cleaners were used to clean floors more frequently." (p.734), and this is consistent with Moykr's (2000) argument that the household preferences for cleanliness changed with household technology.
} 
direction is not clear. If preferences and technology were changing simultaneously, it will be difficult to construct the proper counterfactual needed to estimate the labor savings that technological change brought to the household. For example, decomposing time spent on food would have to separate out the increased time spent on food preparation (sanitation), changes in the availability of foods, and new production technologies, and this will be difficult given the limits of historical data. Not being able to specify an empirically grounded model of home production that would incorporate technological change, time use, and changing preferences is unfortunate- such a model would allow us to make specific welfare calculations based upon these changing economies of scale.

Another possibility is that the Barten model yields predictions which do not generalize to the more than two-good case. Both Horowitz (2002) and Gan and Vernon (2003) make points along this dimension, but Deaton and Paxson (2003) reformulate the Barten model to include multiple goods and still generate the same predictions regarding economies of scale in food. ${ }^{34}$ Gibson (2002) and Gibson and Kim (2007) have suggested that measurement error explains a portion of the "food puzzle" result, and they argue that the problem lay in the recall method use by expenditure surveys. Systematic measurement error in food, however, seems unlikely to explain the trend in the food scale economy estimates since all of the recall evidence (for food and other items) are measured at the same time. Indeed, even after correcting for measurement error in contemporary surveys, Gibson and Kim find that the foodshare is still negatively related to household size. Similarly, Gardes and Starzec (2000) use panel data and confirm that the foodshare is negatively related to household size.

Deaton and Paxson (1998) noted that the unitary nature of the Barten model did pose some problems, but that a collective model was not a likely solution to the "food puzzle." While specifying a fully articulated collective model is beyond the scope of this paper, there is a way of testing some of the general features of a collective approach. Suppose that every individual $i$ will only eat foods in $F_{i}$, a subset of all possible foods $F$. Given a particular distribution in this endowment

\footnotetext{
${ }^{34}$ Deaton and Paxson (2003) give the generalization. Rather than $\left[1-\frac{\partial \ln \phi_{h}(n)}{\partial \ln (n)}\right]\left(\epsilon_{f x}+\epsilon_{f f}\right) \quad>$ $\left[1-\frac{\partial \ln \phi_{f}(n)}{\partial \ln (n)}\right]\left(1+\epsilon_{f f}\right)$, the new formulation becomes $\tilde{\sigma}\left(\epsilon_{f x}+\epsilon_{f f}\right) \quad-\left[1-\frac{\partial \ln \phi_{f}(n)}{\partial \ln (n)}\right]\left(1+\epsilon_{f f}\right)>$ $\sum_{k \neq f} \widetilde{\epsilon}_{f k}\left(\left[1-\frac{\partial \ln \phi_{k}(n)}{\partial \ln (n)}\right]-\tilde{\sigma}\right)$ where $\widetilde{\sigma}$ is the weighted average of the economy of scale factors for all nonfoods and $\widetilde{\epsilon}_{f k}$ is the compensated elasticity of food demand with respect to the price of nonfood $k$. The summation measures the net increase or decrease in food demand caused by substitutions among the nonfoods when household size increases. They further note that "it is hard to think of this [additional] term as providing a resolution of the puzzle." (p. 1380)
} 
over individuals (even allowing for one to be correlated with family background) larger households would have a smaller set of potential foods to eat if they must consume foods in $\cap_{i}^{n} F_{i}$. This "eating at the intersection of desirable foods" would be a solution to the puzzle insofar as larger households would have increased expenditures on food staples (which are arguably more appealing to more people as well as being cheaper than other food items) and lower expenditures on more exotic foods, where tastes are likely to differ. If not, the implications of a collective approach would be similar to those of the Barten model, where larger households would have larger food expenditures to accommodate a greater number of dietary tastes. In demand equations estimated for staple foods (e.g. bread, milk, flour, etc.), it still held that larger households had lower per capita expenditures on staple foods than smaller households. Another possible way of looking at the puzzle would be to estimate the demand for calories, which would be a more direct measure of consumption than food expenditure. Even looking at calories the per capita consumption of calories declines with household size, and even looking at the share of calories devoted to cheap staples the effect of household size on consumption was negative. ${ }^{35}$

This look at historical evidence has sharpened the focus of how the puzzle may be resolved theoretically by considering household production models for food. Testing such models empirically, however, will be difficult as there is significant evidence that both technology and preferences were likely changing over this time period. It is also unclear why a model is necessary for food, but the Barten model suffices to explain clothing, entertainment, and housing expenditures. All told, the "food puzzle" remains, and the existing explanations for the puzzle do not square with the historical evidence.

\section{Conclusion}

If larger households can be welfare equated to smaller households at lower per capita expenditures then household economies of scale are important for measuring living standards. Even more, we would need to know how these economies of scale have changed to accurately measure living standards over time. This paper produced the first comparable historical estimates of household

\footnotetext{
${ }^{35}$ For example, in 1888 the effect of household size on the number of calories $(-0.16)$; fruits and vegetables $(-0.07)$; oils, fats, and sugars (-0.19); meats (-0.07); and cereals (-0.02), were all negative. Even when looking at the share of the diet coming from carbohydrates (which are relatively cheap), the effect of household size was negative (-0.03). See Logan (2006) for estimates of household size's effect on calorie consumption.
} 
economies of scale in an attempt to document trends in economies of scale over time. This look at the past has shown that scale economies in the household changed significantly over time.

The past, however, does not resolve the empirical puzzles with household scale economies. Congruent with contemporary results, food expenditure per capita decreased with household size in the past, although the conditions whereby food expenditure should increase with household size were strongest in the past. While the "food puzzle" remains, the time trend reveals that food has not behaved in any systematic fashion in the past, and that there were fewer scale economies in food in the past than at present. The results here, when combined with the cross-country evidence of Deaton and Paxson, cast serious doubt on the possibility that food was, or will be in the future, a private good consistent with the predictions of the Barten model. More troubling, the existing explanations for the "food puzzle" do not explain these historical results- as such, the "food puzzle" is only made more complicated by looking into the past. Unlike food expenditures, clothing and entertainment behave in a manner more consistent with the model for private goods, where clothing and entertainment expenditures increased with household size. The predictions of the model for public goods holds for the past as well. Housing expenditures decreased with household size in the past. Similarly, household economies of scale varied with household income at every point in time, and the slope of that relationship changed over time as well.

The historical estimates of household scale economies, and the time patterns they suggest, should cause us to rethink our notions of how to detect and measure household economies of scale. While the theoretical conditions are met more in the past than today, the results for food move in exactly the opposite direction. Standard approaches such as household production functions and time use are attractive ideas, but we will need to square such notions with the historical record, which is more difficult than it may first appear. For example, electrification of the household had both income and substitution effects with respect to time, and we will need to search the narrative record more carefully to construct accurate models of household behavior in the past. This avenue of research seems most promising, and still gives us hope that the past holds the key to solving the present puzzle of household scale economies. 


\section{References}

[1] Aguiar, Mark and Erik Hurst (2005). "Consumption versus Expenditure." Journal of Political Economy 113 (5): 919-948.

[2] Aguiar, Mark and Erik Hurst (2006). "Lifecycle Prices and Production." Forthcoming, American Economic Review.

[3] Barten, Anton P. (1964). "Family Composition, Prices and Expenditure Patterns." in Peter E. Hart, Gordon Mills, and John Whitaker, eds. Econometric Analysis for National Planning. London: Butterworths.

[4] Blundell, Richard W., Martin Browning and Ian A. Crawford (2003). "Nonparametric Engel Curves and Revealed Preference." Econometrica 71 (1): 205-240.

[5] Bowden, Sue and Avner Offer (1994). "Household Appliances and the Use of Time: The United States and Britain since the 1920s." Economic History Review 47 (4): 725-748.

[6] Byington, Margaret F. (1910). Homestead: The Households of a Mill Town. Philadelphia: W.M. Fell Co.

[7] Carter, Susan B., Scott Sigmund Gartner, Michael R. Haines, Alan L. Olmstead, Richard Sutch, and Gavin Wright, eds. (2006). Historical Statistics of the United States. New York: Cambridge University Press.

[8] Costa, Dora L. (1999). "American Living Standards: Evidence from Recreational Expenditures." NBER Working Paper No. 7148.

[9] Costa, Dora L. (2001). "Estimating Real Income in the United States from 1888 to 1994: Correcting CPI Bias Using Engel Curves." Journal of Political Economy 109 (6): 1288-1310.

[10] Cowan, Ruth S. (1983). More Work for Mother. New York: Basic Books.

[11] Deaton, Angus (1997). The Analysis of Household Surveys: A Microeconometric Approach to Development Policy. Baltimore, MD: Johns Hopkins.

[12] Deaton, Angus and John Muellbauer (1980). Economics and Consumer Behavior. New York: Cambridge.

[13] Deaton, Angus and Christina Paxson (1998). "Economies of Scale, Household Size, and the Demand for Food." Journal of Political Economy 106 (5): 897-930.

[14] Deaton, Angus and Christina Paxson (2003). "Engel's What? A Response to Gan and Vernon." Journal of Political Economy 111 (6): 1378-1381.

[15] Estes, Eugena and Bo Honore (1995). "Partial Regression Using One Nearest Neighbor." Unpublished Manuscript, Princeton University.

[16] Gardes, Francois and Christophe Starzec (2000). "Economies of Scale and Food Consumption: A Reappraisal of the Deaton-Paxson Paradox." Working Paper No. 2000-08, TEAM, University of Paris I, Pantheon-Sorbonne. 
[17] Gan, Li and Victoria Vernon (2003). "Testing the Barten Model of Economies of Scale in Household Consumption: Toward Resolving a Paradox of Deaton and Paxson." Journal of Political Economy 111 (6): 1361-1377.

[18] Gibson, John (2002). "Why Does the Engel Method Work? Food Demand, Economies of Size and Household Survey Methods." Oxford Bulletin of Economics and Statistics 64 (4): 341-359.

[19] Gibson, John and Bonggeun Kim (2007). "Measurement Error in Recall Surveys and the Relationship between Household Size and Food Demand." American Journal of Agricultural Economics 89 (2): 473-489.

[20] Gorman, William M. (1976). "Tricks with Utility Functions." in M.J. Artis and A.R. Nobay, eds., Essays in Economic Analysis: Proceedings of the 1975 AUTE Conference Sheffield. Cambridge: Cambridge University Press.

[21] Greenwood, Jeremy, Ananth Seshadri and Mehmet Yorukoglu (2005). "Engines of Liberation." Review of Economic Studies 72 (1): 109-133.

[22] Gronau, Ruben and Daniel Hamermesh (2006). "Time vs. Goods: The Value of Measuring Household Production Technologies." Review of Income and Wealth 52 (1): 1-16.

[23] Gronau, Ruben and Daniel Hamermesh (2007). "The Demand for Variety: A Household Production Perspective." Forthcoming, Review of Economics and Statistics

[24] Hamilton, Bruce W. (2001). "Using Engel's Law to Estimate CPI Bias." American Economic Review 91 (3): 619-630.

[25] Horowitz, Andrew W. (2002). "Household Size and the Demand for Food: A Puzzle Resolved?" Unpublished Manuscript, University of Arkansas.

[26] Lewbel, Arthur (1985). "A Unified Approach to Incorporating Demographic and Other Effects Into Demand Systems." Review of Economic Studies 52 (1): 1-18.

[27] Logan, Trevon D. (2005). "The Transformation of Hunger: The Demand for Calories Past and Present." NBER Working Paper No. 11754.

[28] Logan, Trevon D. (2006). "Nutrition and Well-Being in the Late Nineteenth Century." Journal of Economic History 66 (2): 313-341.

[29] Moykr, Joel (2000). "Why 'More Work for Mother?' Knowledge and Household Behavior, 1870-1945." Journal of Economic History 60 (1): 1-41.

[30] Muellbauer, John (1977). "Testing the Barten Model of Household Consumption Effects and the Cost of Children." Economic Journal 87: 460-487.

[31] Nelson, Julie A. (1988). "Household Economies of Scale in Consumption: Theory and Evidence." Econometrica 56 (6): 1301-1314.

[32] Nicholson, J. Leonard (1976). "Appraisal of Different Methods of Estimating Equivalence Scales and Their Results." Review of Income and Wealth 22 (1): 1-11.

[33] Officer, Lawrence H. (2006). "The Annual Consumer Price Index for the United States, 17742005." Measuringworth.com (data series at http://www.measuringworth.com/uscpi/). 
[34] Olney, Martha L. (1991). Buy Now, Pay Later: Advertising, Credit, and Consumer Durables in the 1920s. Chapel Hill, NC: University of North Carolina Press.

[35] Perali, Federico (2001). "The Second Engel Law and Economies of Scale: An Empirical Puzzle to be Resolved." Centre for Household, Income, Labour, and Demographic Economics Working Paper No. 28, University of Torino.

[36] Perali, Federico (2002). "Some Curiosities about the Engel Method to Estimate Equivalence Scales." Economics Bulletin 4 (9):" 1-7.

[37] Pistaferri, Luigi, Todd Schoellman and Michele Tertilt (2005). "Household Size and the Demand for Private Goods." Unpublished Manuscript, Stanford University.

[38] Pollak, Robert A. (1999). "Notes on Time Use." Monthly Labor Review 122 (August): 7-11.

[39] Pollak, Robert A. and Terrence J. Wales (1979). "Welfare Comparisons and Equivalent Scales." American Economic Review 69 (May): 216-221.

[40] Pollak, Robert A. and Terrence J. Wales (1980). "Comparison of the Quadratic Expenditure System and Translog Demand Systems with Alternative Specifications of Demographic Effects." Econometrica 48 (3): 595-612.

[41] Pollak, Robert A. and Terrence J. Wales (1981). "Demographic Variables in Demand Analysis." Econometrica 49 (6): 1533-1551.

[42] Schoellman, Todd and Michele Tertilt (2007). "Families as Roommates: Changes in US Household Size from 1850 to 2000." Unpublished Manuscript, Clemson University.

[43] Smith, Daniel S. (1994). "A Higher Quality of Life for Whom? Mouths to Feed and Clothes to Wear in the Families of Late Nineteenth-Century American Workers." Journal of Family History 19: 1-33.

[44] Vernon, Victoria (2005). "Food Expenditure, Food Preparation Time, and Household Economies of Scale." Unpublished Manuscript, Fashion Institute of Technology, State University of New York.

[45] United States Bureau of Labor Statistics (1951). Handbook of Labor Statistics: 1950 Edition. Bulletin No. 1016. Washington, D.C.: Government Printing Office.

[46] United States Department of Labor (1986). Cost of Living of Industrial Workers in the United States and Europe 1888-1890. ICPSR 7711. Ann Arbor, MI: Inter-university Consortium for Political and Social Research.

[47] United States Department of Labor (1986). Cost of Living in the United States 1917-1919. ICPSR 8299. Ann Arbor, MI: Inter-university Consortium for Political and Social Research.

[48] United States Department of Labor and United States Department of Agriculture (1989). Study of Consumer Purchases in the United States, 1935-1936. ICPSR 8908. Ann Arbor, MI: Inter-university Consortium for Political and Social Research.

[49] Yatchew, Adonis (1997). "An Elementary Estimator of the Partial Linear Model." Economics Letters 57: 135-143. 


\section{Appendix}

\subsection{Notes on the Theory of Household Economies of Scale}

The traditional (Engel) estimates of economies of scale supposes that there is an economies of scale parameter $\theta$ such that $n^{\theta}$ would reflect the fact that for some goods the needs of the household do not increase exactly as much as the number of people. ${ }^{36}$ For this reason, $0 \leq \theta \leq 1$. If $\theta=1$ there would be no economies of scale, whereas if $\theta \in(0,1)$ there would be economies of scale. One could therefore use $1-\theta$ as a measure of household economies of scale. The lower the value of $\theta$ the greater the household scale economy for that particular good. We can think of integrating these economies of scale into the standard household cost function with

$$
c(u, p, n)=n^{\theta} \alpha(p) u^{\beta(p)}
$$

where the cost minimizing function takes effective family size as an argument. This gives us an indirect utility function

$$
\ln u=\frac{\ln x-(\theta \ln n+\ln \alpha(p))}{\beta(p)}
$$

If we use the standard specification that $\ln \alpha(p)=\sum \alpha_{j} \ln p_{j}$ and $\ln \beta(p)=\sum \beta_{j} \ln p_{j}$ the budget share equations (the Engel curve) become

$$
w=\alpha+\beta \ln \left(\frac{x}{n}\right)+\beta(1-\theta) \ln n
$$

and we can compute the economy of scale parameter, which is analogous to the $\phi_{f}$ and $\phi_{h}$ terms in the Barten model depending on the budget share being used.

There are two problems with this specification. The first problem is the identification problem noted by Pollack and Wales (1979). To see this, imaging modifying the household cost function to reflect the fact that additional people have larger or smaller effects that depend of the utility of the household (this is analogous to claiming that the economies of scale themselves are related to the welfare of the household, as the Barten model predicts). In this situation the cost function is now

$$
c(u, p, n)=n^{\theta+\theta_{1} \ln u} \alpha(p) u^{\beta(p)}=n^{\theta} \alpha(p) u^{\beta(p)+\theta_{1} \ln n}
$$

where the budget share equation is again

$$
w=\alpha+\beta \ln \left(\frac{x}{n}\right)+\beta(1-\theta) \ln n
$$

but where now the indirect utility function is

$$
\ln u=\frac{\ln x-(\theta \ln n+\ln \alpha(p))}{\beta(p)+\theta_{1} \ln n}
$$

\footnotetext{
${ }^{36}$ This discussion borrows heavily from Deaton (1997). The idea here is analogous to the standard $A+C^{\theta}$ formula used to derive adult equivalence, where $A$ is the number of adults, $C$ the number of children, and $\theta$ the adult-equivalent factor for children given their age and sex. Just as in the Engel case $0 \leq \theta \leq 1$.
} 
Without some further appeals to substitutions between public and private goods, the Engel method gives us no theoretical basis to call the estimate of $\theta$ a household scale economy. While the Barten model uses the notion of a scaling parameter, it is housed in a discussion of the income and substitution effects that changes in the prices of public and private goods would have on consumption, and the scaling parameter itself is not assumed to be estimated in the functional form employed in the paper. No such case is implied in the Engel methodology or procedure. This lack of theoretical depth has lead some to conclude that "the scaling [Engel] model, although identified on the data once specified, has the same empirical implications as other models in which the economies of scale are clearly different. As a result, whatever it is that the Engel method measures, there are no grounds for claiming that it is economies of scale" (Deaton 1997, p. 268).

The second problem is the restrictions that are placed on the demand function to yield estimates of economies of scale. From the demand equations given above we know that $\theta=1-\frac{\gamma}{\beta}$, where $\gamma$ is the coefficient on the log of household size from the demand equation. For $0 \leq \theta \leq 1$ it must hold that $\frac{\gamma}{\beta} \in[0,1]$, which implies that both $(1)|\gamma| \leq|\beta|$ and that $(2) \operatorname{sign}(\gamma)=\operatorname{sign}(\beta)$. If (1) does not hold the scale economy would be either be greater than 1 or less than $0(0>\theta>1)$, and if (2) does not hold the scale economy would be greater than $1(\theta>1)$. While both of these conditions hold for food in almost all cases, it is not clear that they must hold for other goods. The Engel measure requires that the effect of household size on the budgetshare must be in the same direction as the effect of total expenditures, and the Barten model predicts the opposite for some private goods (such as food). Also, it is not clear why the effect on income must be larger than the effect of household size to compute Engel scale economy estimates. Comparing estimates of $\theta$ for various goods, then, is based upon a conjecture that does not give one firm grounds to make a comparison of economy of scale parameters when using the Engel procedure. Table A1 shows estimates of $\theta$ for the period 1888-1935 for each of the expenditure categories considered in the paper. The results imply that food away from home has more scale economies than food at home, certainly a questionable result. In addition to showing lack of a trend, the results for some expenditures, such a clothing, cannot be interpreted as household economies of scale because they fall outside of the bounds allowed for $\theta$. These historical results confirm the dubious nature of Engel scale economy estimates.

\subsection{Data Appendix}

I used three consumer expenditure surveys in this paper, covering the years 1888-1890, 19171919, and 1935-1936. While theses surveys are not nationally representative, they are broadly comparable and have been used extensively to estimate historical demand systems. For the 18881890 survey, the sample was selected only from the following nine industries: pig iron, bar iron, steel, bituminous coal, coke, iron ore, cotton textile, wool textile and glass. Sample families, limited to those representing more than two persons, were chosen from employer records. These households were then selected to provide detailed expenditure information to survey respondents, and in most instances expenditures were verified by local merchants. Twenty-four states were covered. In total, nearly 7,000 American families were surveyed. For more on the sampling see Logan (2006).

The 1917-1919 data were obtained from the surveys over 12,000 families of wage earners or "small salaried workers." As with the 1888-1890 survey, households were selected from employer records. Sample families were chosen such that there are only husband and wife families with at least one child; the salary earners had to earn less than $\$ 2,000$ per year; families had to reside in the community at least one year prior to the interview; families could not have more than three boarders; families could not be "slum" or "charity"; and non-English-speaking families had to reside in the United States for more than five years. All the selections are from ninety-nine cities 
throughout 42 states.

In the 1935-1936 survey, only native-born families living in the United States were selected. The sample covered 51 cities, 140 villages, and 66 farm counties throughout 30 states. Except for New York City; Columbus, $\mathrm{OH}$; and the South, only white families were chosen. Families in large cities had to earn more than $\$ 500$ a year and those in smaller localities had to earn more than $\$ 250$ a year. There was no income limit on households in this survey, and self-employed households were included as well. The data used in this paper comes from a random sample of 6,000 families of the 61,000 who provided both income and expenditure information. Since the 1935-1936 survey was explicit in its desire to capture the expenditure of rural households, while the 1917-1919 and 1888-1890 selected almost exclusively on urban households, I used only the urban households from the 1935-1936 survey in the analysis, which is more than half of the 6,000 observations. Table A2 shows the means of the expenditure categories and household size for each survey.

Construction of household size in each survey was complicated by the fact that households include a non-negligible number of boarders. All of the results presented in the paper include boarders as household members. This could potentially bias the results, but in estimating the effect of household size on demand with and without boarders the qualitative results were the same. Indeed, including boarders biases the results toward finding economies of scale for the private goods. Since boarders paid rent to the household and shared public goods, their rental payment could be used to increase the consumption of private goods for the other household members. Construction of household expenditure for the three surveys was similar. While the construction of the clothing and food categories was straightforward, housing and entertainment vary somewhat by survey. Entertainment in 1888-1890 is comprised of expenditures on books, newspapers, vacations, and "other amusements." For 1917-1919 entertainment includes expenditures on movies, concerts, plays, lectures, dances, billiards, excursions, books, and "other amusements." For 1935-1936 entertainment includes movies, radios, sports clubs, social clubs, camping, fishing, hiking, sports (golf, baseball, horseback riding, tennis, etc.), bikes, skates, skis, billiards, boats, cameras, vacations, and "other recreational expenses." Housing in every survey year includes both rent and/or mortgage payments, lighting, and fuel expenditures. For 1917-1919 and 1935-1936, the list expands to include utilities such as electricity and sewage. I also constructed a housing expenditure variable that included expenditures on furniture and appliances, as these are likely goods to be used by and/or for multiple household members. The results in the text with regards to housing are robust to the inclusion of furniture and appliances, and other expenditures such as alcohol and tobacco prove to be weakly consistent with the predictions for private goods in the Barten model (see Table A3). 
Figure 1

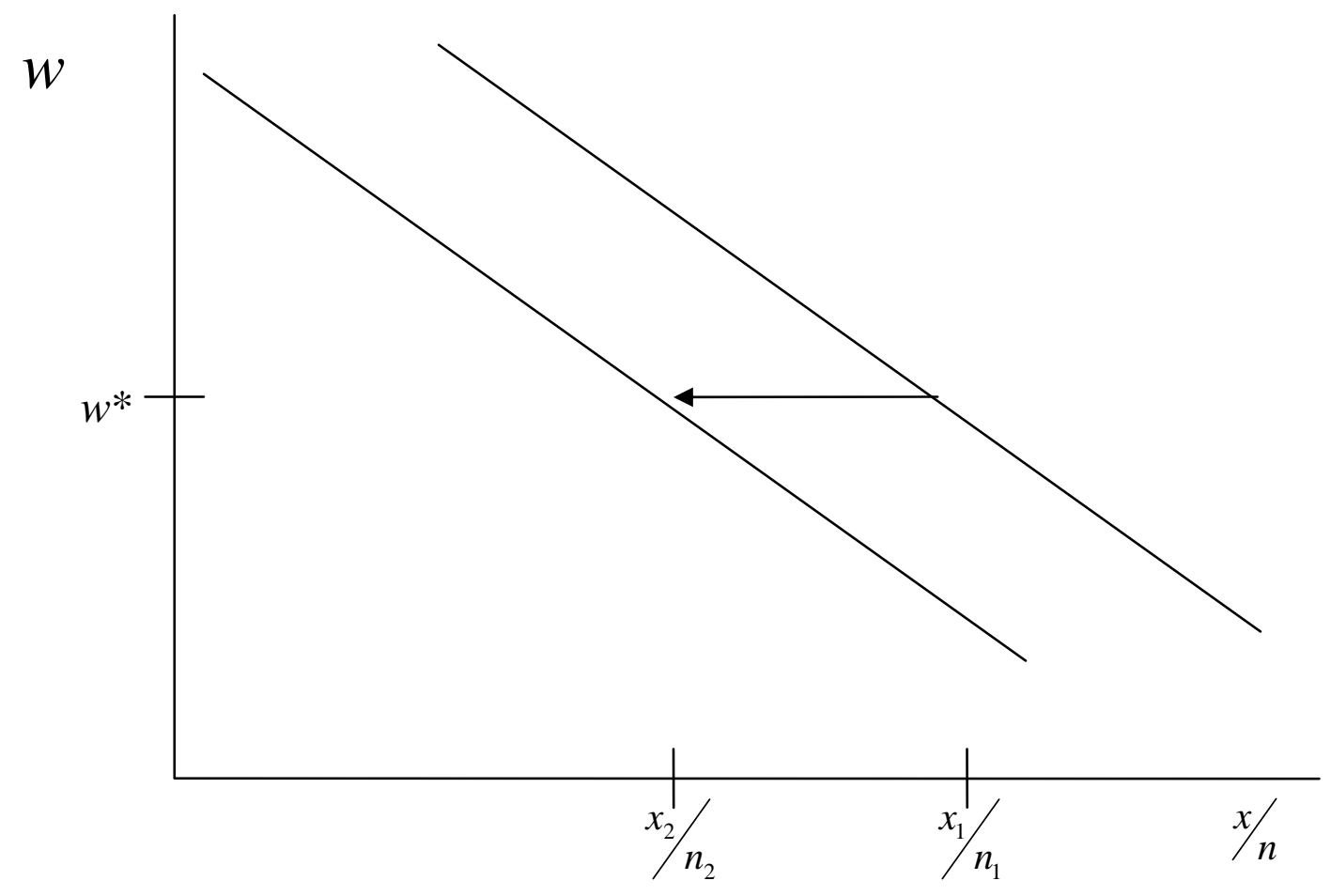

Engel Measures of Economies of Scale 
Table 1

The Effect of Household Size on Food's Share of the Budget 1888-1935

\begin{tabular}{lccc}
\hline & I & II & III \\
Method & 1888 & 1917 & 1935 \\
\hline \hline Linear (OLS) & -0.023 & -0.091 & -0.040 \\
& $(5.6)$ & $(32.39)$ & $(3.36)$ \\
& & & \\
Fourier & -0.022 & -0.089 & -0.051 \\
& $(5.16)$ & $(31.67)$ & $(4.32)$ \\
& & & \\
First Differencing & -0.026 & -0.090 & -0.054 \\
& $(6.27)$ & $(31.97)$ & $(4.27)$ \\
& & & -0.038 \\
IV & -0.024 & -0.083 & $(3.06)$ \\
\hline \hline
\end{tabular}

Note:

Each entry is the coefficient estimate for the log of household size for that method, year pairing. The dependent variable in each regression is the share of household expenditure devoted to food. Each entry comes from a separate regression that includes the log of per capita expenditure, the fraction of the household employed, the state of residence, the industry of the household head, and demographic shares of the household in five year age-sex categories.

Robust t-statistics are listed under coefficient estimates in parentheses.

See section 3 of the text for details on each estimation procedure (method). 
Table 2

The Effect of Household Size on Food's Budget Share by Consumption Type 1917-1935

\begin{tabular}{|c|c|c|c|c|}
\hline \multirow[b]{2}{*}{ Method } & \multicolumn{2}{|c|}{ Food at Home } & \multicolumn{2}{|c|}{ Food Away from Home } \\
\hline & $\begin{array}{c}\text { I } \\
1917 \\
\end{array}$ & $\begin{array}{c}\text { II } \\
1935 \\
\end{array}$ & $\begin{array}{c}\text { III } \\
1917 \\
\end{array}$ & $\begin{array}{c}\text { IV } \\
1935 \\
\end{array}$ \\
\hline Linear (OLS) & $\begin{array}{c}-0.097 \\
(34.35)\end{array}$ & $\begin{array}{c}-0.046 \\
(4.5)\end{array}$ & $\begin{array}{l}0.006 \\
(5.84)\end{array}$ & $\begin{array}{l}0.008 \\
(2.39)\end{array}$ \\
\hline Fourier & $\begin{array}{c}-0.096 \\
(33.72)\end{array}$ & $\begin{array}{l}-0.044 \\
(4.32)\end{array}$ & $\begin{array}{l}0.007 \\
(6.08)\end{array}$ & $\begin{array}{l}0.008 \\
(2.27)\end{array}$ \\
\hline First Differencing & $\begin{array}{c}-0.096 \\
(33.83)\end{array}$ & $\begin{array}{l}-0.035 \\
(3.23)\end{array}$ & $\begin{array}{l}0.006 \\
(5.62)\end{array}$ & $\begin{array}{l}0.006 \\
(1.65)\end{array}$ \\
\hline IV & $\begin{array}{c}-0.089 \\
(30.36) \\
\end{array}$ & $\begin{array}{r}-0.053 \\
(5.07) \\
\end{array}$ & $\begin{array}{l}0.007 \\
(5.94) \\
\end{array}$ & $\begin{array}{l}0.010 \\
(2.77) \\
\end{array}$ \\
\hline $\mathrm{N}$ & 12817 & 3534 & 12817 & 3534 \\
\hline
\end{tabular}

Note:

Each entry is the coefficient estimate for the log of household size for that method, year pairing. The dependent variable in each regression is the share of household expenditure devoted to food at home (I-II) and away from home (III-IV).

Each entry comes from a separate regression that includes the log of per capita expenditure, the fraction of the household employed, the state of residence, the industry of the household head, and demographic shares of the household in five year age-sex categories.

Robust t-statistics are listed under coefficient estimates in parentheses.

See section 3 of the text for details on each estimation procedure (method). 
Table 3

The Effect of Household Size on Clothing's Share of the Budget 1888-1935

\begin{tabular}{lccc}
\hline & I & II & III \\
Method & 1888 & 1917 & 1935 \\
\hline \hline Linear (OLS) & 0.068 & 0.040 & 0.029 \\
& $(21.78)$ & $(17.83)$ & $(5.23)$ \\
& & & \\
Fourier & 0.069 & 0.044 & 0.028 \\
& $(21.78)$ & $(19.31)$ & $(4.96)$ \\
& & & \\
First Differencing & 0.063 & 0.048 & 0.028 \\
& $(19.87)$ & $(21.31)$ & $(4.91)$ \\
& & & \\
IV & 0.082 & 0.049 & 0.035 \\
& $(24.91)$ & $(20.99)$ & $(6.08)$ \\
\hline \hline
\end{tabular}

Note:

Each entry is the coefficient estimate for the log of household size for that method, year pairing.

The dependent variable in each regression is the share of household expenditure devoted to clothing. Each entry comes from a separate regression that includes the log of per capita expenditure, the fraction of the household employed, the state of residence, the industry of the household head, and demographic shares of the household in five year age-sex categories.

Robust t-statistics are listed under coefficient estimates in parentheses. 
Table 4

The Effect of Household Size on Entertainment's Share of the Budget 1888-1935

\begin{tabular}{lccc}
\hline & I & II & III \\
Method & 1888 & 1917 & 1935 \\
\hline \hline Linear (OLS) & 0.007 & 0.004 & 0.005 \\
& $(5.75)$ & $(9.63)$ & $(1.93)$ \\
& & & \\
Fourier & 0.006 & 0.004 & 0.005 \\
& $(5.1)$ & $(10.0)$ & $(1.94)$ \\
& & & \\
First Differencing & 0.006 & 0.004 & 0.003 \\
& $(4.82)$ & $(10.5)$ & $(0.89)$ \\
& & & 0.008 \\
IV & 0.010 & 0.005 & $(2.89)$ \\
\hline \hline
\end{tabular}

Note:

Each entry is the coefficient estimate for the log of household size for that method, year pairing.

The dependent variable in each regression is the share of household expenditure devoted to leisure/ entertainment/recreation.

Each entry comes from a separate regression that includes the log of per capita expenditure, the fraction of the household employed, the state of residence, the industry of the household head, and demographic shares of the household in five year age-sex categories.

Robust t-statistics are listed under coefficient estimates in parentheses.

See section 3 of the text for details on each estimation procedure (method).

See the data appendix for the expenditure categories that comprise entertainment. 
Table 5

The Effect of Household Size on Housing's Share of the Budget 1888-1935

\begin{tabular}{lccc}
\hline & I & II & III \\
Method & 1888 & 1917 & 1935 \\
\hline \hline Linear (OLS) & -1.538 & -0.068 & -0.029 \\
& $(3.54)$ & $(22.41)$ & $(3.63)$ \\
& & & \\
Fourier & -1.560 & -0.067 & -0.025 \\
& $(3.59)$ & $(21.85)$ & $(3.17)$ \\
& & & \\
First Differencing & -1.666 & -0.065 & -0.022 \\
& $(3.86)$ & $(21.4)$ & $(2.72)$ \\
& & & -0.035 \\
IV & 0.787 & -0.069 & $(4.31)$ \\
\hline \hline
\end{tabular}

Note:

Each entry is the coefficient estimate for the log of household size for that method, year pairing. The dependent variable in each regression is the share of household expenditure devoted to housing. Each entry comes from a separate regression that includes the log of per capita expenditure, the fraction of the household employed, the state of residence, the industry of the household head, and demographic shares of the household in five year age-sex categories.

Robust t-statistics are listed under coefficient estimates in parentheses.

See section 3 of the text for details on each estimation procedure (method).

See the data appendix for the expenditure categories that comprise housing expenditures. 
Table 6

The Effect of Household Size on Budget Shares by Income Quartile, 1888-1935

\begin{tabular}{|c|c|c|c|c|}
\hline Category & & & & \\
\hline Food & $1 \mathrm{st}$ & 2nd & $3 r d$ & 4th \\
\hline 1888 & $\begin{array}{l}-0.007 \\
(0.71)\end{array}$ & $\begin{array}{c}-0.014 \\
(1.89)\end{array}$ & $\begin{array}{r}-0.032 \\
(4.09)\end{array}$ & $\begin{array}{l}-0.027 \\
(2.66)\end{array}$ \\
\hline 1917 & $\begin{array}{c}-0.075 \\
(12.82)\end{array}$ & $\begin{array}{c}-0.087 \\
(15.61)\end{array}$ & $\begin{array}{c}-0.105 \\
(19.15)\end{array}$ & $\begin{array}{c}-0.094 \\
(16.04)\end{array}$ \\
\hline 1935 & $\begin{array}{r}-0.026 \\
(0.96) \\
\end{array}$ & $\begin{array}{c}-0.058 \\
(2.23) \\
\end{array}$ & $\begin{array}{r}-0.072 \\
(3.18) \\
\end{array}$ & $\begin{array}{r}-0.047 \\
(2.53) \\
\end{array}$ \\
\hline Clothing & $1 \mathrm{st}$ & 2nd & $3 r d$ & 4th \\
\hline 1888 & $\begin{array}{c}0.075 \\
(10.43)\end{array}$ & $\begin{array}{c}0.065 \\
(11.34)\end{array}$ & $\begin{array}{l}0.057 \\
(9.51)\end{array}$ & $\begin{array}{l}0.054 \\
(7.16)\end{array}$ \\
\hline 1917 & $\begin{array}{l}0.050 \\
(12.0)\end{array}$ & $\begin{array}{c}0.053 \\
(12.33)\end{array}$ & $\begin{array}{c}0.039 \\
(8.8)\end{array}$ & $\begin{array}{c}0.022 \\
(4.0)\end{array}$ \\
\hline 1935 & $\begin{array}{c}0.022 \\
(1.97) \\
\end{array}$ & $\begin{array}{r}0.033 \\
(2.93) \\
\end{array}$ & $\begin{array}{r}0.032 \\
(2.82) \\
\end{array}$ & $\begin{array}{l}0.036 \\
(3.28) \\
\end{array}$ \\
\hline Entertainment & $1 \mathrm{st}$ & 2nd & $3 r d$ & 4th \\
\hline 1888 & $\begin{array}{c}-0.003 \\
(1.83)\end{array}$ & $\begin{array}{l}0.004 \\
(2.39)\end{array}$ & $\begin{array}{l}0.003 \\
(1.18)\end{array}$ & $\begin{array}{l}0.004 \\
(0.93)\end{array}$ \\
\hline 1917 & $\begin{array}{l}0.001 \\
(1.33)\end{array}$ & $\begin{array}{l}0.005 \\
(5.97)\end{array}$ & $\begin{array}{l}0.006 \\
(6.22)\end{array}$ & $\begin{array}{l}0.000 \\
(0.18)\end{array}$ \\
\hline 1935 & $\begin{array}{l}0.004 \\
(0.76) \\
\end{array}$ & $\begin{array}{c}0.009 \\
(1.4)\end{array}$ & $\begin{array}{c}0.001 \\
(0.2) \\
\end{array}$ & $\begin{array}{r}0.013 \\
(1.84) \\
\end{array}$ \\
\hline Housing & $1 \mathrm{st}$ & $2 n d$ & $3 r d$ & 4th \\
\hline 1888 & $\begin{array}{r}-5.259 \\
(4.26)\end{array}$ & $\begin{array}{r}-0.790 \\
(0.95)\end{array}$ & $\begin{array}{c}-0.457 \\
(0.6)\end{array}$ & $\begin{array}{l}0.062 \\
(0.08)\end{array}$ \\
\hline 1917 & $\begin{array}{r}-0.065 \\
(11.4)\end{array}$ & $\begin{array}{c}-0.060 \\
(10.25)\end{array}$ & $\begin{array}{c}-0.067 \\
(11.02)\end{array}$ & $\begin{array}{c}-0.082 \\
(11.53)\end{array}$ \\
\hline 1935 & $\begin{array}{r}-0.020 \\
(0.86)\end{array}$ & $\begin{array}{r}-0.034 \\
(1.66)\end{array}$ & $\begin{array}{r}-0.036 \\
(1.89)\end{array}$ & $\begin{array}{r}-0.053 \\
(2.97)\end{array}$ \\
\hline
\end{tabular}

Note:

Each entry is the coefficient estimate for the log of household size for that income quartile, year pairing for that expenditure category, whose budget share is the dependent variable in the regression.

Each entry comes from a separate OLS regression that includes the log of per capita expenditure, the fraction of the household employed, the state of residence, the industry of the household head, and demographic shares of the household in five year age-sex categories.

Robust t-statistics are listed under coefficient estimates in parentheses. 
Table 7

The Effect of Household Size on Food and Clothing's Share of the Budget 1888-1935

\begin{tabular}{lccc}
\hline & I & II & III \\
Method & 1888 & 1917 & 1935 \\
\hline \hline \multirow{2}{*}{ Linear (OLS) } & 0.045 & -0.050 & -0.016 \\
& $(10.25)$ & $(15.11)$ & $(1.25)$ \\
Fourier & 0.047 & -0.046 & -0.024 \\
& $(10.75)$ & $(13.65)$ & $(1.89)$ \\
First Differencing & -0.026 & & 0.003 \\
& $(6.85)$ & 0.020 & $(0.23)$ \\
IV & 0.057 & $(7.17)$ & -0.003 \\
& $(12.56)$ & -0.033 & $(0.24)$ \\
\hline \hline & & $(9.53)$ & 3534 \\
\hline
\end{tabular}

The Effect of Household Size on Food in Food and Housing Expenditures 1888-1935

\begin{tabular}{lccc} 
& I & II & III \\
Method & 1888 & 1917 & 1935 \\
\hline \hline \multirow{2}{*}{ Linear (OLS) } & -0.017 & 0.048 & -0.033 \\
& $(1.18)$ & $(10.22)$ & $(2.24)$ \\
Fourier & -0.017 & 0.047 & -0.032 \\
& $(1.17)$ & $(10.08)$ & $(2.17)$ \\
First Differencing & 0.001 & -0.024 & 0.019 \\
& $(0.1)$ & $(7.01)$ & $(1.4)$ \\
IV & -0.092 & 0.053 & -0.048 \\
& $(6.09)$ & $(10.93)$ & $(10.59)$ \\
\hline \hline
\end{tabular}

Note:

Each entry is the coefficient estimate for the log of household size for that method, year pairing. The dependent variable in each regression is the share of household expenditure devoted to food and clothing (top panel) and the share of expenditure devoted to food from food and housing expenditure (bottom panel). Each entry comes from a separate regression that includes the log of per capita expenditure, the fraction of the household employed, the state of residence, the industry of the household head and demographic shares of the household in five year age-sex categories.

Robust t-statistics are listed under coefficient estimates in parentheses.

See section 3 of the text for details on each estimation procedure (method). 
Table A1

Engel Estimates of Household Economies of Scale, 1888-1935

\begin{tabular}{lccc}
\hline & I & II & III \\
& 1888 & 1917 & 1935 \\
\hline \hline Food & 0.809 & 0.426 & 0.709 \\
Food at Home & & 0.448 & 0.520 \\
Food Away from Home & & 0.313 & 0.378 \\
& & & -1.956 \\
Clothing & -2.851 & -0.0005 & 0.597 \\
Entertainment & 0.714 & 0.398 & 19.038 \\
Housing & 0.708 & 0.002 & \\
\hline N & & & 3534 \\
\hline \hline
\end{tabular}

Note:

Estimates are from OLS regressions reported in Tables 1-5, where the budgetshare is regressed on per capita expenditure, household characteristics, geographic location, and industry. The Engel measure of household scale economies is calculated as the coefficient on househld size divided by the coefficient estimate on per capita expenditure subtracted from unity.

Low values imply large household economies of scale, since the value here is the power by which the effective household size increases for that consumption good with an additional member of the household. 
Table A2

Summary Statistics from Historical Household Surveys, 1888-1935

\begin{tabular}{cccc}
\hline & I & II & III \\
Variable & 1888 & 1917 & 1935 \\
\hline \hline Household Size & 4.7 & 4.9 & 3.7 \\
& $(2.11)$ & $(1.64)$ & $(1.45)$ \\
Food Share & $44.5 \%$ & $39.2 \%$ & $38.9 \%$ \\
& $(.089)$ & $(.079)$ & $(.093)$ \\
Clothing Share & $16.7 \%$ & $16.2 \%$ & $10.9 \%$ \\
& $(.065)$ & $(.050)$ & $(.056)$ \\
Entertainment Share & $1.9 \%$ & $3.2 \%$ & $3.5 \%$ \\
& $(.024)$ & $(.009)$ & $(.027)$ \\
Housing Share & $13.7 \%$ & $13.6 \%$ & $14.3 \%$ \\
& $(.081)$ & $(.069)$ & $(.088)$ \\
& & & \\
\hline \hline
\end{tabular}

Note: Estimates are the mean values, based on Author's calculation.

Standard Deviations are listed in parentheses. 
Table A3

The Effect of Household Size on Housing and Furniture's Share of the Budget 1888-1935

\begin{tabular}{lccc}
\hline & I & II & III \\
Method & 1888 & 1917 & 1935 \\
\hline \hline \multirow{2}{*}{ Linear (OLS) } & -1.476 & -0.053 & -0.026 \\
& $(3.41)$ & $(15.01)$ & $(3.04)$ \\
Fourier & -1.502 & -0.052 & -0.022 \\
& $(3.47)$ & $(14.47)$ & $(2.56)$ \\
First Differencing & -1.673 & -0.052 & -0.019 \\
& $(3.88)$ & $(14.66)$ & $(2.14)$ \\
IV & 0.072 & -0.056 & -0.033 \\
& $(1.6)$ & $(15.19)$ & $(3.67)$ \\
\hline \hline
\end{tabular}

The Effect of Household Size on Alcohol and Tobacco's Share of the Budget 1888-1935

\begin{tabular}{lccc}
\hline & I & II & III \\
Method & 1888 & 1917 & 1935 \\
\hline \hline \multirow{2}{*}{ Linear (OLS) } & 0.005 & 0.002 & 0.008 \\
& $(1.19)$ & $(1.1)$ & $(1.14)$ \\
Fourier & 0.006 & 0.002 & 0.008 \\
& $(1.47)$ & $(1.15)$ & $(1.18)$ \\
First Differencing & -0.004 & & -0.001 \\
& $(1.37)$ & 0.000 & $(0.11)$ \\
IV & 0.008 & $(0.33)$ & 0.007 \\
& $(2.08)$ & 0.002 & $(0.88)$ \\
\hline \hline & & $(1.11)$ & 3534 \\
\hline
\end{tabular}

Note:

Each entry is the coefficient estimate for the log of household size for that method, year pairing.

The dependent variable in each regression is the share of household expenditure devoted to housing, furniture, and appliances (top panel) and share of expenditure devoted to alchohol and tobacco (bottom panel). Each entry comes from a separate regression that includes the log of per capita expenditure, the fraction of the household employed, the state of residence, the industry of the household head and demographic shares of the household in five year age-sex categories.

Robust t-statistics are listed under coefficient estimates in parentheses.

See section 3 of the text for details on each estimation procedure (method).

See the data appendix for the expenditure categories that comprise housing expenditures. 